\section{No diabetes}

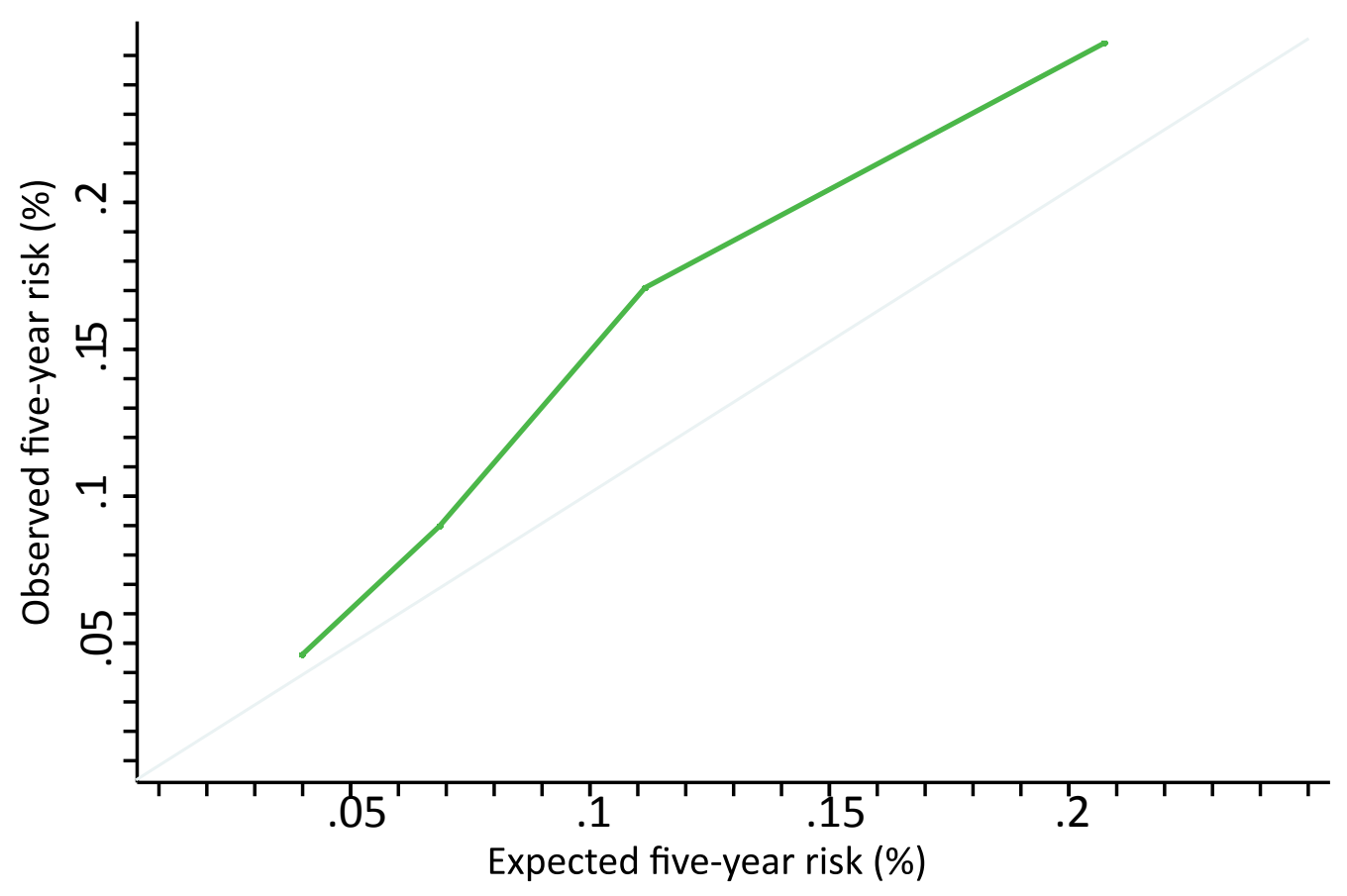

\section{Diabetes}

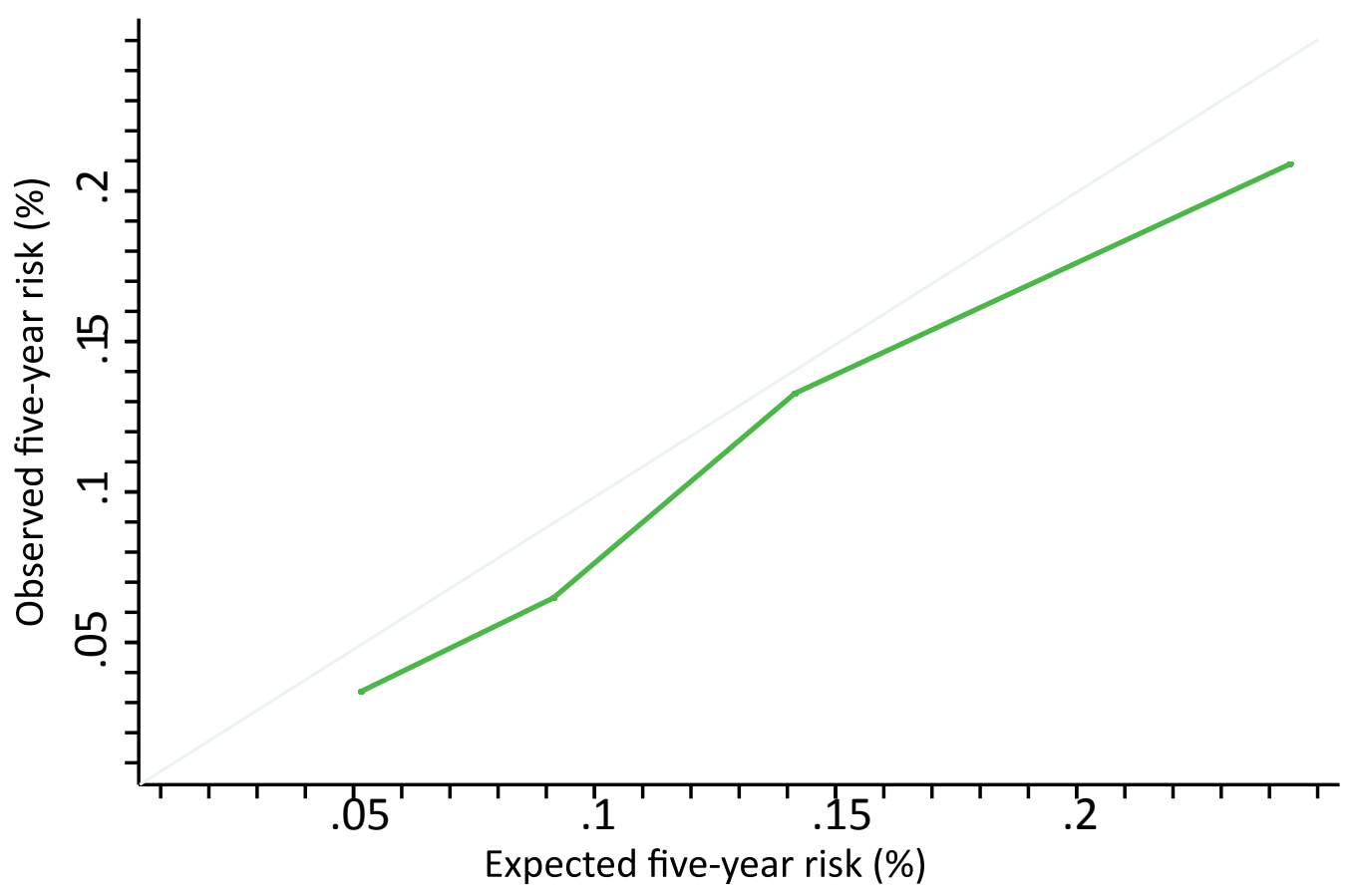

\section{No BP-lowering drugs}

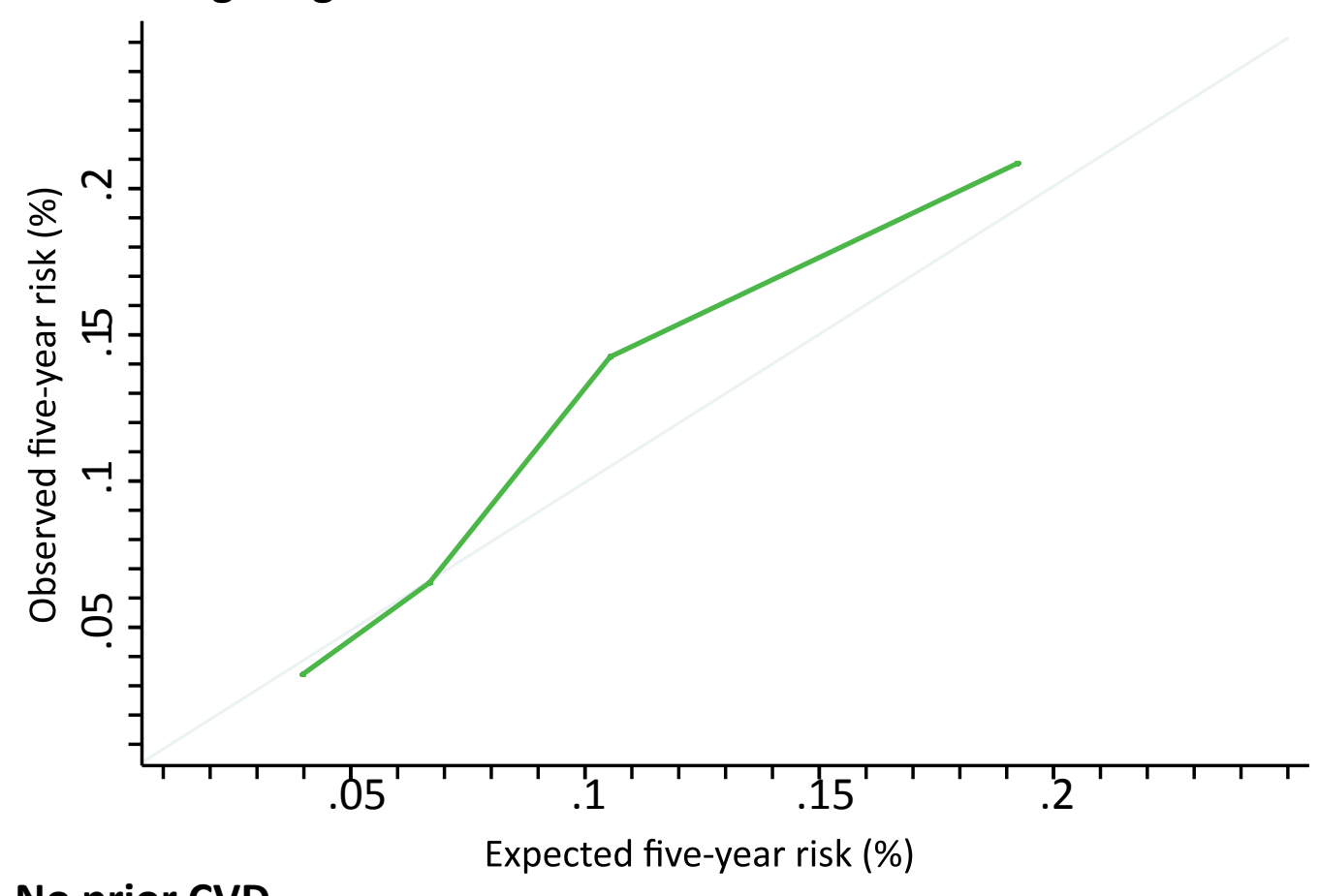

No prior CVD

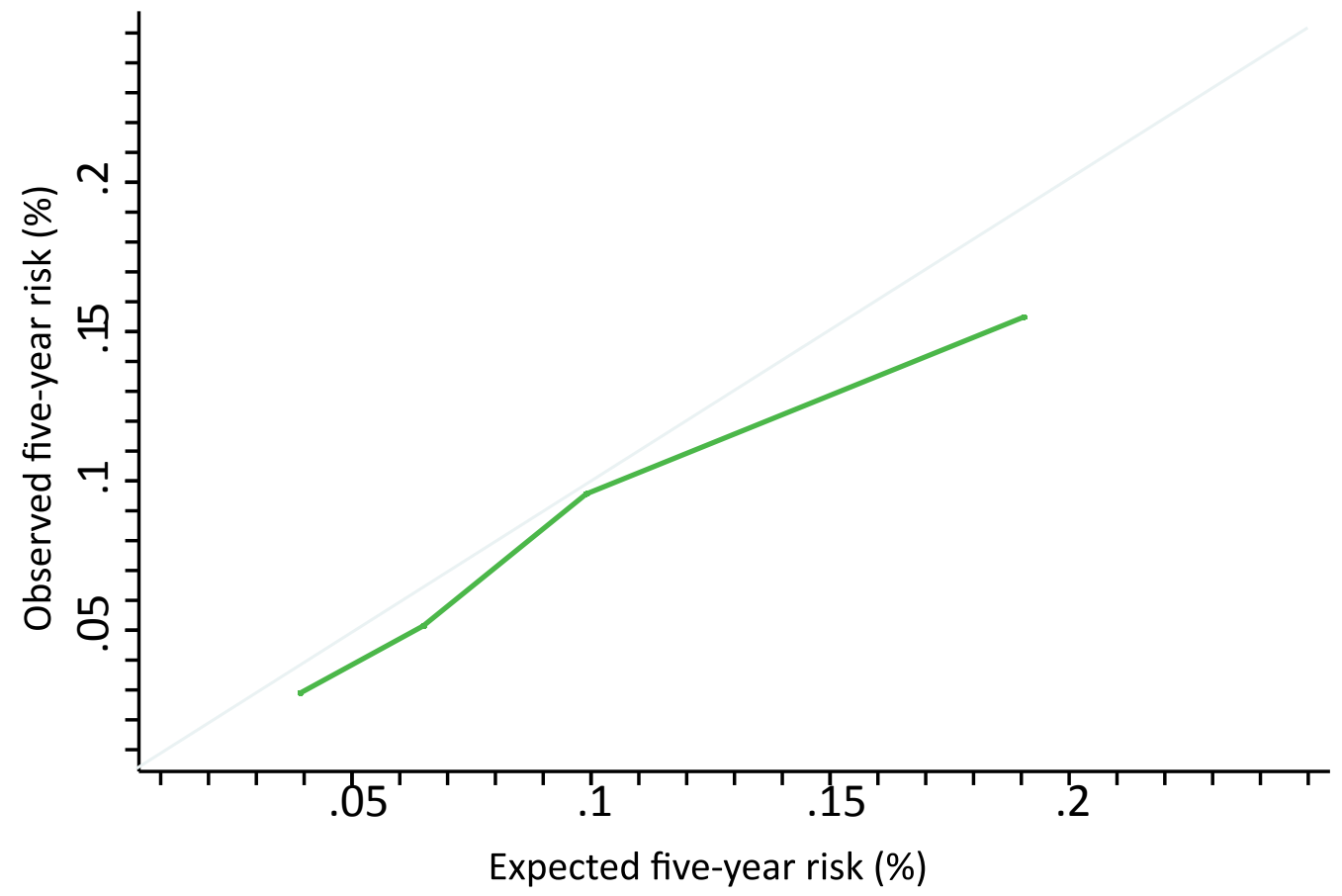

\section{BP-lowering drugs}

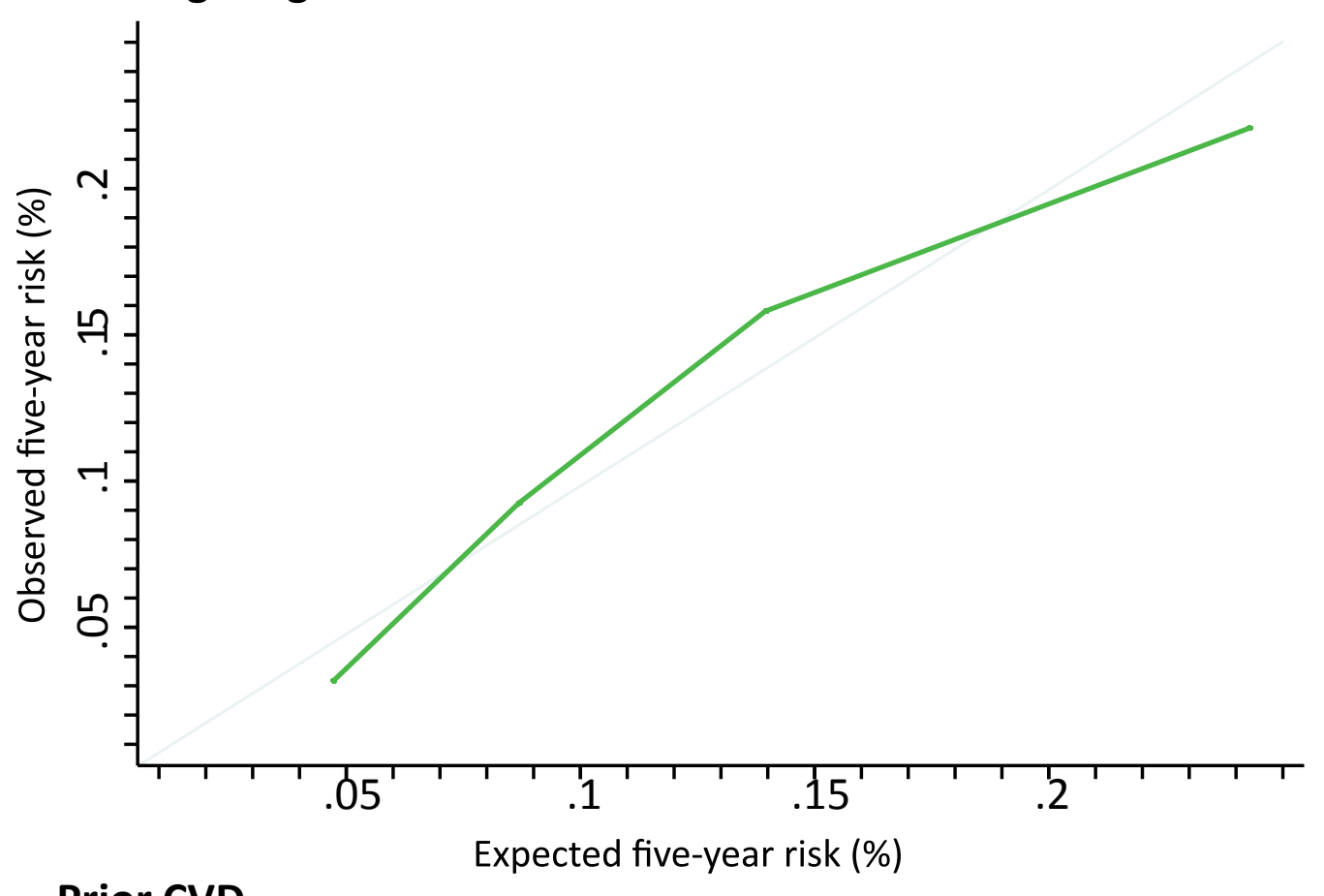

Prior CVD

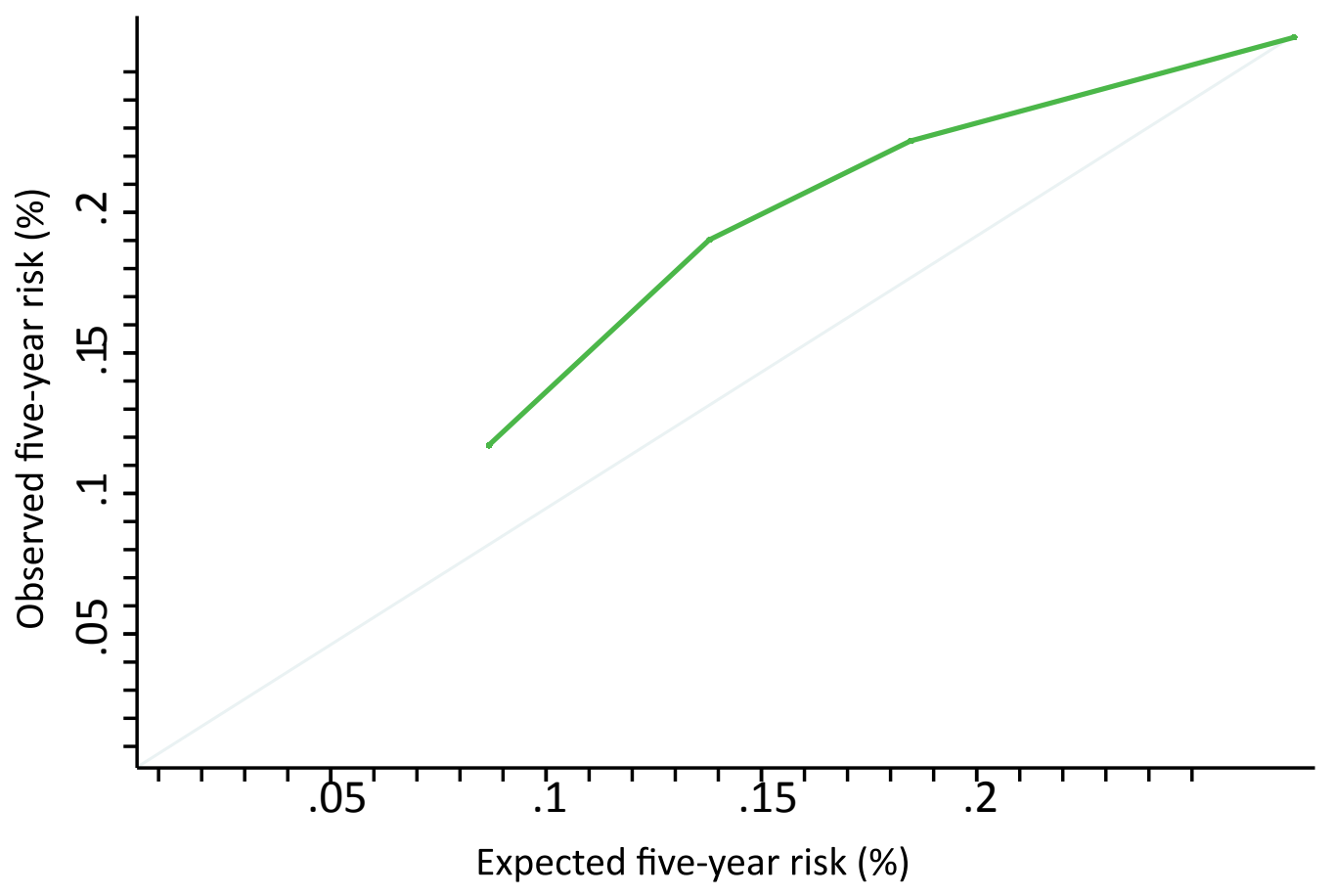

